\title{
Pfizer to buy Wyeth in \$68-billion deal
}

One of the world's biggest pharmaceutical companies is set to get even larger. Pfizer announced on 26 January that it intends to acquire Wyeth, a company with a strong reputation in biologics and vaccines.

The combined company - united under the name Pfizer - would be a behemoth, with nearly 130,000 employees and more than US $\$ 71$ billion in revenue. Pfizer will pay about $\$ 68$ billion for Wyeth, based in Madison, New Jersey, an unusually large deal given the current financial crisis. The acquisition, expected to close late this year, will draw on Pfizer's cash and stock resources, along with a loan of $\$ 22.5$ billion, backed by a syndicate of five banks, some of which recently received bailout funds from the US government.

The deal comes as Pfizer nears the expiry dates of its patents on several key drugs, including atorvastatin (Lipitor), a cholesterol medication that is the best-selling drug in the world.

Over the past two years, Pfizer has shed 16,000 employees, closed 15 manufacturing sites, and culled research programmes (see Nature 456, 6-7; 2008). The company now says it intends to cut 19,500 more jobs, losing 15\% of its workforce. This includes 8,000 job losses announced before the Wyeth purchase.

Both Wyeth and Pfizer have strong research

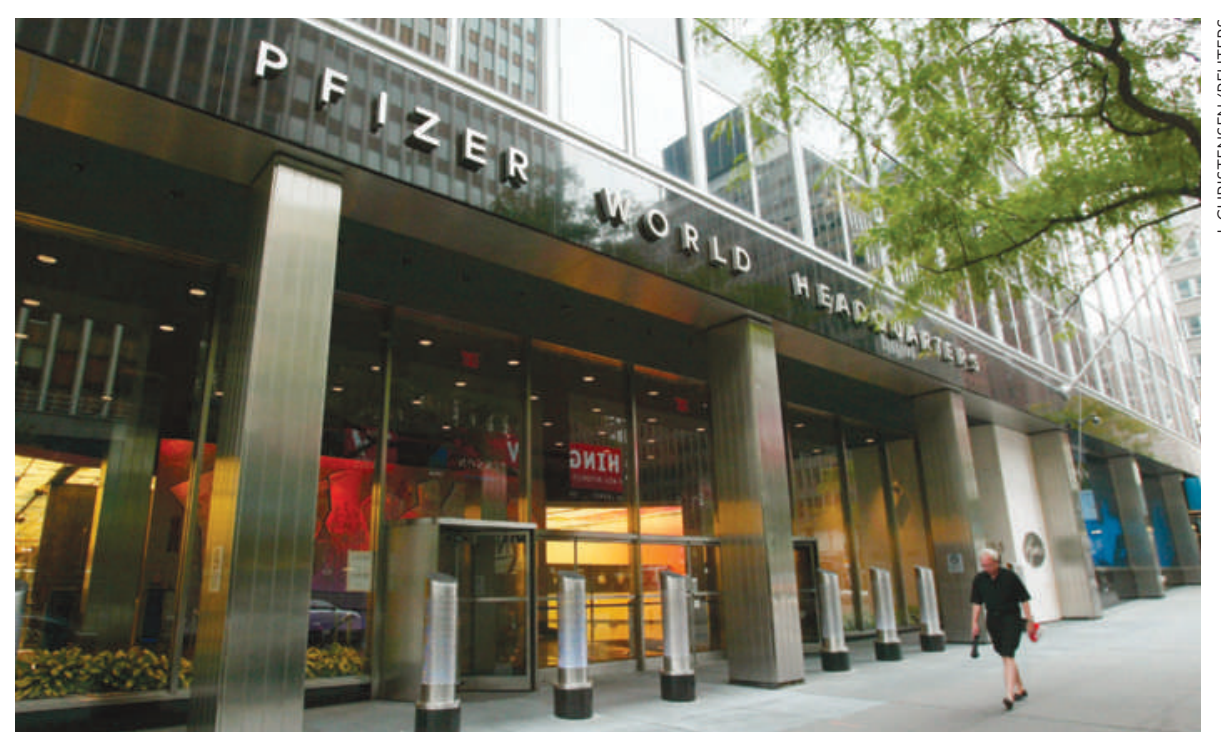

Pfizer's headquarters in New York, where Pfizer and Wyeth announced that they would merge.

programmes in diseases of the central nervous system, such as Alzheimer's disease, and in animal health-care products. But Pfizer chief executive Jeffrey Kindler says that the Wyeth acquisition will diversify Pfizer's pipeline, particularly in vaccines and in biologics - drugs comprised of complex biological molecules.
In the short term, Wyeth can bolster Pfizer's portfolio with two top-selling products. The pneumococcal conjugate vaccine (Prevnar) against meningitis in infants and children is the world's best-selling vaccine, and etanercept (Enbrel) - an arthritis and psoriasis therapy that Wyeth markets with Amgen of Thousand

\section{Ocean fertilization: dead in the water?}

The theory that adding iron to the oceans can help suck up atmospheric carbon dioxide cheaply and efficiently has received a further blow. A study ${ }^{1}$ published in this week's issue of Nature (see page 577) finds that the potential of iron-induced carbon sequestration is far lower than previously estimated.

During the CROZEX experiment in 2004 and 2005, scientists on board the British vessel RSS Discovery observed the impact of natural iron fertilization on algal growth and carbon export near the Crozet Islands, an archipelago some 2,000 kilometres southeast of South Africa. The team found that, relative to one unit of added iron, the amount of carbon sequestered to 200 metres' depth, where it will stay for a couple of decades, was almost 80 times smaller than the amount that scientists had determined during a similar study in the nearby Kerguelen region².

"Ecosystem response and carbon export seem to vary very substantially from region to region," says Ulrich Bathmann, a biological oceanographer at the Alfred Wegener Institute (AWI) for Polar and Marine Research in Bremerhaven, Germany, who was not involved in the new study. "And the closer you look, the more complex the story gets."

Separately, on 26 January, the German science ministry gave the green light to LOHAFEX, an Indo-German ocean-fertilization experiment that has been waiting to get going in the Southern Ocean. Responding to environmental and political concerns, the ministry had ruled on 13 January that an independent assessment be carried out before the experiment could start ${ }^{3}$. From aboard the German vessel RV Polarstern, the LOHAFEX team plans to dump 20 tonnes of iron sulphate into a 300-square-kilometre area between Argentina and the Antarctic Peninsula.

The CROZEX study, led by Raymond Pollard of the National Oceanography Centre in Southampton, UK, looked instead at natural ocean fertilization, in which iron-rich dust blowing off the Crozet Islands settles on the waters. The team observed that some 270 tonnes of iron triggered a two- to threefold increase in biological productivity over an area the size of Ireland. But sediment probes revealed that the export of carbon to the deep ocean was nowhere near as massive as the Kerguelen study, and lab experiments, had suggested.

Although the study design allowed for only a rough estimate of carbon sequestration, the findings are sobering. Previously, scientists had cautioned that removing $30 \%$ of the carbon released every year as a result of human activity would require treating an ocean area ten times larger than the entire Southern Ocean, the most fertile waters for iron seeding ${ }^{4}$. Scaled up, the CROZEX results imply that even if the world's total ocean surface had a craving for iron, satisfying that would not have a large effect on the levels of atmospheric $\mathrm{CO}_{2}$.

"You might get a different response if you shock the system by dumping a lot of iron all at once," says Pollard. "The effect will still be much 
